\title{
Using Two-component Epoxy Resin for Asphalt Pavement Applications-Part B: Stiffness and Relaxation
}

\author{
Fusong Wang ${ }^{1, a}$, Chao $\mathrm{Li}^{2, \mathrm{~b}}$, Yue Xiao ${ }^{3, \mathrm{c}}$, Shaopeng $\mathrm{Wu}^{4, \mathrm{~d}}$
}

${ }^{1}$ State Key Laboratory of Silicate Materials for Architectures, Wuhan University of Technology, Wuhan, 430070, China

${ }^{2}$ State Key Laboratory of Silicate Materials for Architectures, Wuhan University of Technology, Wuhan, 430070, China

${ }^{3}$ State Key Laboratory of Silicate Materials for Architectures, Wuhan University of Technology, Wuhan, 430070, China

${ }^{4}$ State Key Laboratory of Silicate Materials for Architectures, Wuhan University of Technology, Wuhan, 430070, China

aemail: 18202772328@163.com, bemail: Lic@whut.edu.cn,

cemail: xiaoy@whut.edu.cn, demail: wusp@whut.edu.cn

Keywords: Epoxy resin, Dynamic mechanic analysis, Relaxation, Asphalt pavement.

Abstract. The stiffness of fully cured two-component epoxy resin was studied by means of Dynamic Mechanic Analysis (DMA) in this research, as well as the temperature sensitivity and frequency sensitivity. The relaxation properties was included, both one fully cured resin and oven aged resin. Research results illustrates that the investigated two-component epoxy resin behaves as a rubbery elastic material and will not give viscous permanent deformation problems at temperatures above 60 ${ }^{\circ} \mathrm{C}$. The epoxy resin has bitumen-like viscoelastic properties at lower temperature, while behaves as an elastic material and show very good high temperature resistance at higher temperature. The relaxation of the original epoxy resin is far less than the relaxation percentage of bituminous binders and epoxy modified bitumen. Research results approve that the oven ageing has hardly influence on the relaxation of epoxy resin.

\section{Introduction}

In part A of the paper, the curing behaviors were presented. The results indicated that the direct tensile strength of fully cured epoxy resin can reach to $20 \mathrm{MPa}$, while its failure strain of epoxy resin is very small and not sensitive to the temperature and displacement rate. In this part, DMA was perfomed to further characterize the temperature sensitivity and frequency (related to the loading speed) sensitivity.

The oxygen ageing resistance was also investigated in relaxation tests. The fully cured specimens were divided into two groups. One group, which presents the original (or not aged) binders, was directly used for tests. The other group was placed in an oven for ageing before tests. The oven was used for simulating the influence of high temperature ageing. Fully cured specimens were placed in the oven for 7 days at $85{ }^{\circ} \mathrm{C}$ with ventilated air.

\section{Materials and Methodologies}

Materials. Same two-component epoxy resin was used in this research. All the specimens involved in this part of study were fully cured.

Dynamic Mechanic Analysis. DMA was used to investigate the viscoelastic properties of the binder, specifically at the higher temperature range of $60^{\circ} \mathrm{C}$ to $170{ }^{\circ} \mathrm{C}$. DMA is commonly used to determine the stiffness and phase angle of materials, by measuring the amplitude and phase difference of the displacement of a sample in response to an applied oscillating force [1]. The complex modulus, storage modulus and loss modulus can be obtained with the following equation: 


$$
E^{*}=\frac{\sigma_{\max }}{\varepsilon_{\max }}
$$

Where: $E^{*}$ is the complex modulus [Pa]; $\sigma_{\max }$ is the applied maximum sinusoidal stress [Pa]; $\varepsilon_{\max }$ is the maximum sinusoidal strain. The lag between the applied stress and the resulting strain during sinusoidal loading is defined as phase angle. It is an indicator of the relative amounts of recoverable and non-recoverable deformation. The larger the phase angle is, the more viscous the material will be. Purely elastic materials have a phase angle of 0 degrees, while purely viscous materials have a phase angle of 90 degrees. So the phase angle can be regarded as a measure of the viscoelasticity of the material.

Relaxation test. The same dumbbell shape specimens, as presented in Part A, were used for relaxation tests at $0{ }^{\circ} \mathrm{C}, 10^{\circ} \mathrm{C}$ and $20^{\circ} \mathrm{C}$. The test was performed in three steps. First, the specimens were conditioned in the testing machine at the specified test temperature for 60 minutes. Then a constant displacement rate of $1 \mathrm{~mm} /$ minute was applied till a certain force was reached, which was $40 \%$ of the failure force of fully cured samples. After that, the displacement was kept constant for 10 minutes and the relaxation of the resulting force was monitored. The relaxation percentage after 10 minutes was calculated by using the following equation [2]:

$$
\mathrm{R}=\left(1-\frac{F_{\text {remain }}}{F_{\text {Maxapplied }}}\right) \times 100
$$

Where, $\mathrm{R}$ is the relaxation percentage after 10 minutes, [\%]; $F_{\text {remain }}$ is the remaining force after relaxation at certain time, [N]; $F_{\text {Maxapplied }}$ is the maximum applied force, [N].

\section{Research Results Analysis}

DMA results. The dimension of test DMA specimens were $30 \mathrm{~mm}$ long, $8 \mathrm{~mm}$ wide and $2 \mathrm{~mm}$ thick. A DMA temperature sweep test ranging from $24{ }^{\circ} \mathrm{C}$ to higher than $170{ }^{\circ} \mathrm{C}$ was conducted on fully cured epoxy resin. Three frequencies of $1 \mathrm{~Hz}, 10 \mathrm{~Hz}$ and $100 \mathrm{~Hz}$ were used. Fig. 1 shows the test results. One can clearly observe that at high temperatures (more than $100{ }^{\circ} \mathrm{C}$ ), the investigated epoxy resin behaves as a rubbery elastic material and has a stiffness value above $10 \mathrm{MPa}$ while its phase angle value is close to 5 degree. It will not give viscous permanent deformation problems at temperatures above $60^{\circ} \mathrm{C}$, like traditional bitumen do.

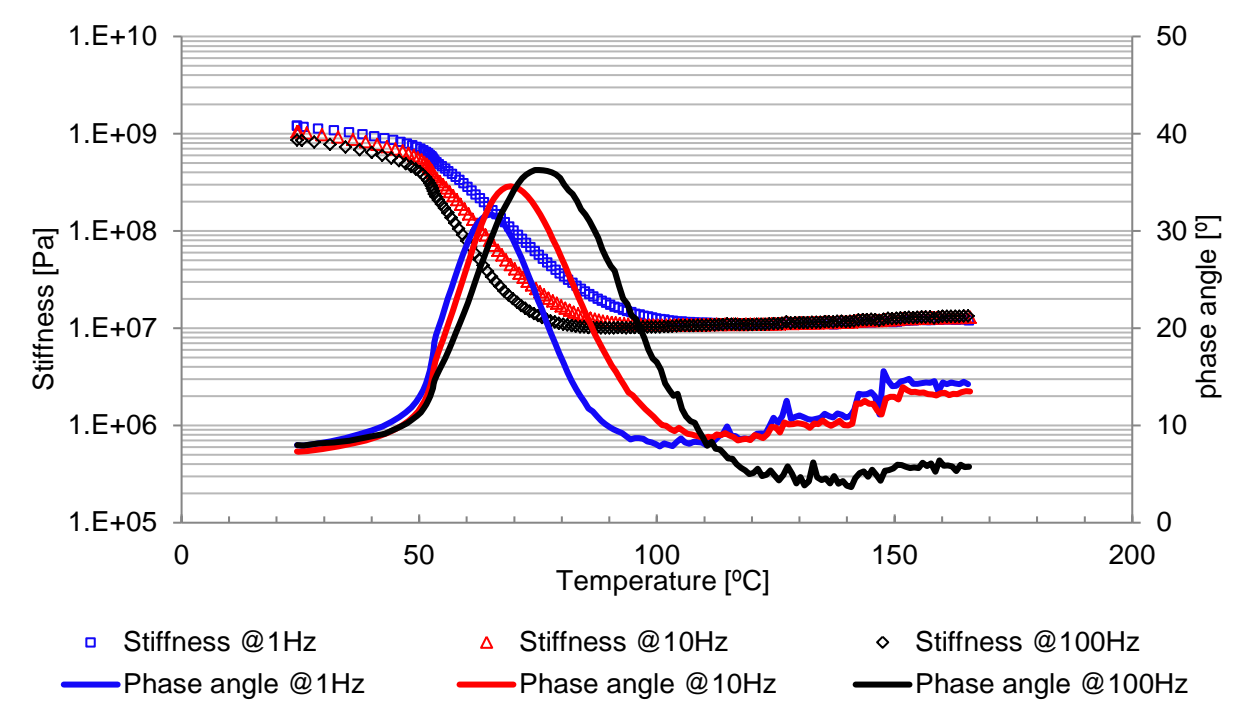

Fig. 1 Temperature sweep results of epoxy resin

Fig. 1 also indicates that the phase angle curves of epoxy resin at $1 \mathrm{~Hz}, 10 \mathrm{~Hz}$ and $100 \mathrm{~Hz}$ reach their maximum phase angle at $65.3{ }^{\circ} \mathrm{C}, 69.2{ }^{\circ} \mathrm{C}$ and $74.4{ }^{\circ} \mathrm{C}$. This information shows that at lower temperature (lower than the temperature where the phase angle reaches its peak value), the bitumen component dominates the binder properties. Hence at this temperature range, the epoxy resin will 
have bitumen-like viscoelastic properties. At higher temperatures (higher than the temperature where the phase angle reaches its peak value), the epoxy component dominates the binder property, and the epoxy resin binder will behave as an elastic material and show very good high temperature resistance.

Table 1 illustrates the influence of frequencies on the epoxy resin at $25^{\circ} \mathrm{C}$ and $40{ }^{\circ} \mathrm{C}$. It shows that at $25^{\circ} \mathrm{C}$ and $40{ }^{\circ} \mathrm{C}$, the frequency has only a slight influence on the binder stiffness and phase angle. At the temperature range from $50{ }^{\circ} \mathrm{C}$ to $100{ }^{\circ} \mathrm{C}$, higher frequencies will result in a higher stiffness. But when the temperature is lower than $20^{\circ} \mathrm{C}$, as Fig. 1 shows, the stiffness and phase angle of epoxy resin are independent of the frequency. This approved that the applied displacement rate does not seem to have a significant effect on the tensile strength, since the difference in tensile strength between $10{ }^{\circ} \mathrm{C}$ and $20^{\circ} \mathrm{C}$ is not significant as discussed in Part A.

Furhermore, the stiffness curves approved that the tensile strength tests were performed under conditions where the response of the binder is independent of loading frequency. This can therefore explain why the influence of loading rate on the failure strain cannot be determined in Part A.

Table 1 Influence of frequencies on the binder stiffness

\begin{tabular}{|c|c|c|c|c|}
\hline \multirow{2}{*}{ Frequency [Hz] } & \multicolumn{2}{|c|}{ Stiffness [Pa] } & \multicolumn{2}{c|}{ Phase angle [Degree] } \\
\cline { 2 - 5 } & $25{ }^{\circ} \mathrm{C}$ & $40{ }^{\circ} \mathrm{C}$ & $25{ }^{\circ} \mathrm{C}$ & $40{ }^{\circ} \mathrm{C}$ \\
\hline 1 & $8.62 \mathrm{E}+08$ & $6.39 \mathrm{E}+08$ & 7.968547 & 9.47036 \\
\hline 10 & $1.04 \mathrm{E}+09$ & $7.77 \mathrm{E}+08$ & 7.296724 & 8.830232 \\
\hline 100 & $1.19 \mathrm{E}+09$ & $9.37 \mathrm{E}+08$ & 7.962769 & 8.927408 \\
\hline
\end{tabular}

Relaxation. Direct Tensile Strength results between the original epoxy resin and oven aged epoxy resin was first studied before perfoming relaxation analysis. Table 2 presents the results. Obviously, after oven ageing at higher temperature, the tensile strength of epoxy resin has slightly increased under the same displacement loading rate. But considering the variability during the tensile tests, the influence of ageing on the tensile strength and failure strain is not significant. This means that the high temperature ageing procedure did not have significant influence on the binder strength behavior. The high temperature resistance was also investigated by means of relaxation tests.

Table 2 DTS of original epoxy resin and aged epoxy resin with $1 \mathrm{~mm} / \mathrm{min}$

\begin{tabular}{|c|c|c|c|c|c|c|c|}
\hline \multicolumn{2}{|c|}{} & \multicolumn{3}{c|}{ Failure Strength [MPa] } & \multicolumn{3}{c|}{ Failure Strain [\%] } \\
\hline \multicolumn{2}{|c|}{ Temperature } & $0{ }^{\circ} \mathrm{C}$ & $10^{\circ} \mathrm{C}$ & $20{ }^{\circ} \mathrm{C}$ & $0{ }^{\circ} \mathrm{C}$ & $10^{\circ} \mathrm{C}$ & $20{ }^{\circ} \mathrm{C}$ \\
\hline \multirow{3}{*}{ Aged } & Test No. 1 & 29.47 & 20.36 & 23.72 & 11.54 & 11.36 & 11.36 \\
\cline { 2 - 8 } & Test No. 2 & 30.75 & 19.83 & 21.86 & 7.9 & 8.22 & 11.98 \\
\cline { 2 - 8 } & Average & 30.11 & 20.1 & 22.79 & 9.72 & 9.79 & 11.67 \\
\hline \multicolumn{2}{|c|}{ Original } & 28.01 & 20.47 & 18.5 & 10.4 & 8.33 & 9.35 \\
\hline
\end{tabular}

Fig. 2 shows the relaxation curves of the original and aged epoxy resin at $10{ }^{\circ} \mathrm{C}$. The applied maximum force on aged binder in the relaxation test was slightly higher than the one applied on the original binder. This was because the high temperature ageing resulted in higher tensile strength, as presented in Table 2. 


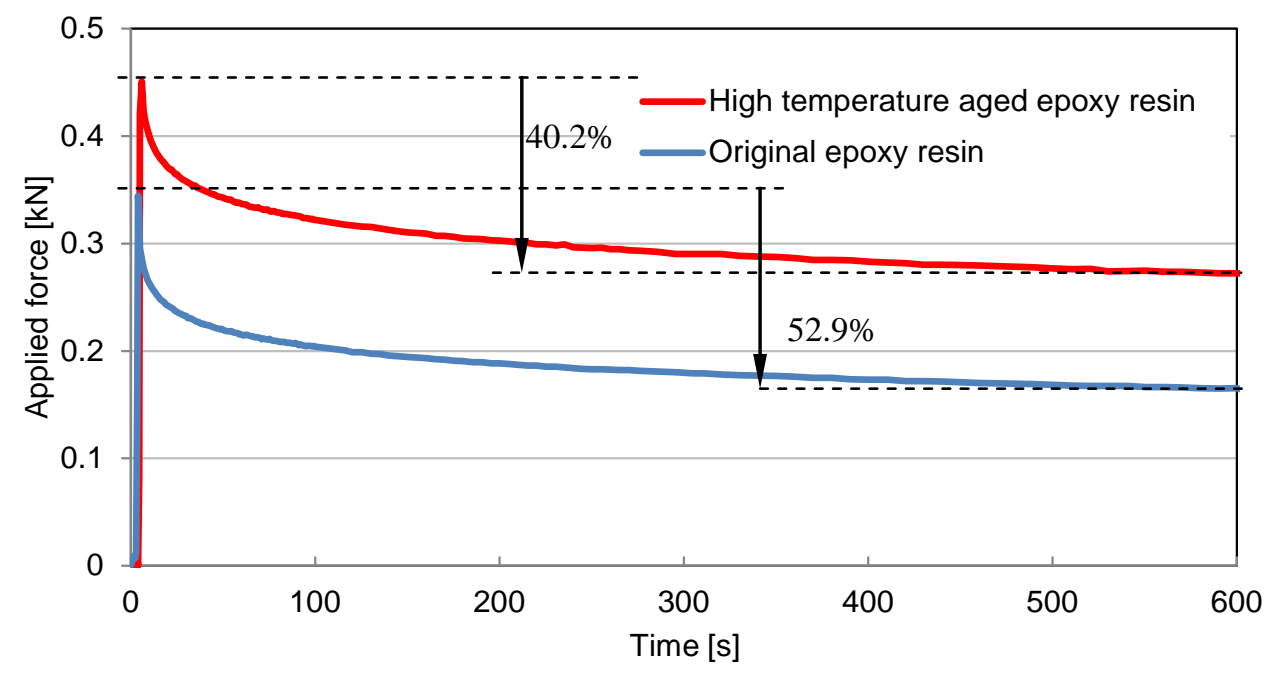

Fig. 2 Relaxation test results at $10{ }^{\circ} \mathrm{C}$ of epoxy resin before and after ageing

The relaxation of the original epoxy resin at $0{ }^{\circ} \mathrm{C}$ is $39.24 \%$, which is far less than the relaxation percentage of bituminous binders and epoxy modified bitumen. The relaxation percentage of original bitumen is normally higher than $90 \%$ at $0{ }^{\circ} \mathrm{C}$, while epoxy modified bitumen can reach more than $50 \%$ relaxation under the same test conditions [3]. Epoxy resin is a more elastic material, while bitumen and EMB are viscoelastic materials. Pavement surface layers should have the ability to release the temperature induced tensile stresses which will occur in winter condition. But for the investigated epoxy resin, about $40 \%$ to $60 \%$ of the applied temperature stresses will remain and when high enough these stresses in combination with traffic induced stresses might result in cracking. Further research is therefore recommended to improve this investigated epoxy resin to achieve better relaxation behavior at lower temperature conditions.

Table 3 compares the average relaxation percentage between the original and oven aged epoxy resin binders at three different temperatures. After 7 days oven ageing, the aged binder shows less relaxation at $10{ }^{\circ} \mathrm{C}$. It decreased from $48.8 \%$ to $40.8 \%$. But at $20^{\circ} \mathrm{C}$ and $0{ }^{\circ} \mathrm{C}$, the difference is limited. Again, it approved that the ageing has hardly influence on the relaxation of epoxy resin.

Table 3 Relaxation test results for epoxy resin

\begin{tabular}{|c|c|c|c|c|c|c|c|}
\hline \multicolumn{2}{|c|}{} & \multicolumn{3}{c|}{ Relaxation [\%] } & \multicolumn{3}{c|}{ Applied strain [\%] } \\
\hline \multicolumn{2}{|c|}{ Temperature } & $20{ }^{\circ} \mathrm{C}$ & $10^{\circ} \mathrm{C}$ & $0{ }^{\circ} \mathrm{C}$ & $20^{\circ} \mathrm{C}$ & $10^{\circ} \mathrm{C}$ & $0{ }^{\circ} \mathrm{C}$ \\
\hline \multirow{4}{*}{ Original } & Specimen 1 & 50.7 & 44.6 & 39.7 & 3.1 & 2.5 & 2.3 \\
\cline { 2 - 8 } & Specimen 2 & 50.4 & 52.9 & 38.8 & 3.1 & 2.5 & 2.4 \\
\cline { 2 - 8 } & Specimen 3 & 52.6 & -- & -- & 2.3 & -- & -- \\
\cline { 2 - 8 } & Average & 51.21 & 48.76 & 39.24 & & & \\
\hline \multirow{3}{*}{ Aged } & Specimen 1 & 52.1 & 40.2 & 37.3 & 2.8 & 2.8 & 2.5 \\
\cline { 2 - 8 } & Specimen 2 & 51.2 & 41.4 & 38.5 & 3.1 & 3.1 & 2.5 \\
\cline { 2 - 8 } & Average & 51.67 & 40.78 & 37.92 & & & \\
\hline
\end{tabular}

\section{Summary}

Based on the research results obtained from the Dynamic Mechanic Analysis and relaxation tests on two-component epoxy resin, the following items can be concluded:

1. The investigated two-component epoxy resin behaves as a rubbery elastic material and will not give viscous permanent deformation problems at temperatures above $60{ }^{\circ} \mathrm{C}$. The epoxy resin has bitumen-like viscoelastic properties at lower temperature, while behaves as an elastic material and show very good high temperature resistance at higher temperature.

2. At the lower temperature conditions, the stiffness and phase angle of epoxy resin are independent of the frequency. 
3. The relaxation of the original epoxy resin is far less than the relaxation percentage of bituminous binders and epoxy modified bitumen. Research results approve that the oven ageing has hardly influence on the relaxation of epoxy resin.

\section{Acknowledgement}

The project was supported by the International Science \& Technology Cooperation Program of China (No. 2013DFE83100), the Open Fund of the Key Laboratory of Highway Engineering in Special Regions of Ministry of Education of China, Chang'an University (No. 310821161105), the Open Fund of the Key Laboratory of Road Structure and Material of Ministry of Transport (Changsha University of Science \& Technology, No. kfj150302) and the Scientific Research Foundation for Returned Overseas Chinese Scholars, State Education Ministry.

\section{References}

[1] G. Cerni, F. Cardone, and S. Colagrande, Low-Temperature Tensile Behaviour of Asphalt Binders: Application of Loading Time-Temperature-Conditioning Time Superposition Principle, Constr. Build. Mater. 25 (2011), 2133-45.

[2] L. Pang, K.Y. Liu, S.P. Wu, M. Lei, and Z.W. Chen, Effect of Ldhs on the Aging Resistance of Crumb Rubber Modified Asphalt, Constr. Build. Mater. 67, Part B (2014), 239-43.

[3 Y. Xiao, M. van de Ven, A. Molenaar, Z. Su, and F. Zandvoort, Characteristics of Two-Component Epoxy Modified Bitumen, Mater. Struct. 44 (2011), 611-22. 